\title{
BMJ Open Study protocol for a cluster randomised controlled trial testing the effectiveness of the 'High schools High on life' intervention on reducing excessive drinking in Danish high schools
}

\author{
Veronica Sofie Clara Pisinger (1D), Sofie Hoffmann, Johanne Aviaja Rosing, \\ Morten Grønbæk, Janne Schurmann Tolstrup, Lau Thygesen, Rikke Krølner
}

To cite: Pisinger VSC, Hoffmann S, Rosing JA, et al. Study protocol for a cluster randomised controlled trial testing the effectiveness of the 'High schools High on life' intervention on reducing excessive drinking in Danish high schools. BMJ Open 2020;10:e038857. doi:10.1136/ bmjopen-2020-038857

- Prepublication history for this paper is available online. To view these files, please visit the journal online (http://dx.doi org/10.1136/bmjopen-2020038857).

Received 27 March 2020 Revised 04 June 2020 Accepted 19 June 2020

Check for updates

(C) Author(s) (or their employer(s)) 2020. Re-use permitted under CC BY-NC. No commercial re-use. See rights and permissions. Published by BMJ.

National Institute of Public Health, University of Southern Denmark, Copenhagen, Syddanmark, Denmark

Correspondence to

Dr Veronica Sofie Clara Pisinger; vepi@sdu.dk

\section{ABSTRACT}

Introduction This paper describes the evaluation design of the 'High schools High on life' intervention; a schoolbased intervention to reduce excessive drinking among high school students in Denmark. The intervention includes a school environmental component to limit access to alcohol at school, a school-educational component to change social norms around alcohol among first year students and a parental component addressing parents' knowledge and attitudes towards alcohol.

Methods and design The study will employ a cluster randomised controlled study design and will include a random sample of 16 high schools randomly allocated 1:1 to either intervention or control group. Target group: first year high school students. Timeline: baseline survey: January to March 2019, collected as part of the Danish National Youth Study 2019. Delivery of intervention: April 2019 to March 2020. Follow-up survey: April to May 2020. Primary outcome measure: $30 \%$ reduction in mean number of binge-drinking episodes (five or more alcoholic drinks on one occasion) within the last 30 days. Secondary outcome measures: proportion of students who drink alcohol, mean weekly alcohol consumption, alcohol intake at last school party, alcohol intake at the school during last school party, proportion of students who agree to be able to have fun at a party without drinking and the proportion of students who think alcohol plays a too dominant part at the school. Implementation will be monitored through process evaluation.

Ethics and dissemination The Scientific Ethics Committees for the Capital Region of Denmark has declared that the trial is not subject to notification (jnr. 19021957). The study is registered at the Research an Innovation Office at University of Southern Denmark (ref: 10.314) allowing collection of personal data. Results will be published in peer-reviewed journals.

Trial registration number NCT03906500.

\section{INTRODUCTION}

Alcohol is associated with an increased risk of more than 60 alcohol-related diseases ${ }^{1}$ and is estimated to be the leading risk factor for

\section{Strengths and limitations of this study}

- The study will test the effect of the 'High schools High on life' intervention in a cluster randomised controlled trial in a real-life setting.

- The 'High schools High on life' intervention will provide insights into effective strategies to reduce excessive alcohol consumption among Danish adolescents, where excessive drinking is the norm.

- The study will provide knowledge on implementation processes, and intervention effects among different subgroups, and contribute to the literature on cultural changes in alcohol use in educational institutions.

- A longer follow-up period may be required than originally anticipated, to cause and measure cultural changes within high schools.

death among 15-24years old, worldwide. ${ }^{2}$ Binge drinking (in Denmark defined as consumption of five or more alcoholic drinks (12 $\mathrm{g}$ of pure alcohol) on one occasion) is common among adolescents in most western countries, and Danish adolescents have one of the highest levels of drunkenness worldwide. ${ }^{3}$ The age of drinking onset has increased within the last 30 years, ${ }^{45}$ however, when young Danes begin high school their alcohol consumption often escalates. ${ }^{6} 7$ During high school start, students meet new people, join new peer groups and attend social events at the high school and outside the school where drinking is the focal point. These experiences contribute to the formation of perceived norms about high school alcohol consumption. Among Danish high school students (15-20years old), 28\% (35\% boys and 24\% girls) have been binge drinking four or more times within the last 30 days, and 20\% drink above the Danish Board of Health's high risk 
drinking limits for adults (21 units a week for men and 14 units a week for women) ${ }^{8}$

In the short term, alcohol use in adolescence can lead to injuries, homicide, suicide, violence, criminal activity, poor health and risky sexual behaviour. ${ }^{9}$ Furthermore, excessive alcohol use in the teenage years often tracks into and through adulthood, and early drinking onset increases the risk of high alcohol consumption and alcohol dependence later in life. ${ }^{10-14}$

Beside structural prevention strategies, such as limiting availability through increases in prices and a high minimum purchasing age, intervention in the school setting has been proposed to be one of the most feasible strategies to tackle substance use disorders among adolescents. ${ }^{15}$ Numerous school-based substance abuse prevention programmes have been developed to postpone debut age or reduce use of substances in young adolescents. However, effects of the programmes have been mixed. ${ }^{16-18}$ A systematic review of school-based drug-prevention programmes showed that the most effective programmes used interactive delivery methods, used peer leaders and focused on affecting peer norms. ${ }^{19}$ Interventions targeting older adolescents (15-20years old) are mostly American college interventions, ${ }^{2021}$ high-risk interventions based on screening and brief motivational interviewing ${ }^{22}{ }^{23}$ or webbased personalised normative feedback interventions. ${ }^{24}$ Systematic reviews suggest that college-based interventions that include educational intervention strategies such as personalised feedback, moderation strategies (on how to avoid drinking too much), expectancy challenge (challenge expectancies of when it is fun and not fun to drink), identification of risky situations, and goal setting are effective in reducing alcohol-related behaviour issues among adolescents. ${ }^{18}$ However, evidence from the American college literature is difficult to transfer to the Danish high school setting, in which alcohol is easily accessible. In Denmark, alcohol is a strongly integrated part of the school culture, and a large group of the students drink excessively with the purpose of intoxication. ${ }^{26}{ }^{27}$ Danish students, in all ages, are allowed to drink and buy alcohol at high school parties, because high school parties are perceived to be private parties, at which the national age limits of being served or purchasing alcohol (respectively 18 years and 16 years) is not enforced. ${ }^{26}$ It can be hypothesised that educational strategies cannot stand alone in Denmark and should be combined with school environmental strategies targeting physical, structural, social and cultural environment for drinking at schools. However, we have not been able to identify previous studies using a multicomponent approach. There is thus a lack of interventions targeting high school students excessive drinking focusing on environmental strategies and social norms approaches to effectively reduce adolescent binge drinking.

The overall aim of the 'High schools High on life' study is to implement and evaluate a multicomponent high school-based intervention to reduce excessive drinking among high school students. The aim of this study protocol is to describe the effect and process evaluation design of the 'High schools High on life' intervention.

\section{Hypothesis and research questions of the effect and process evaluation study}

We hypothesise that the 'High schools High on life' intervention will create a $30 \%$ reduction in binge drinking episodes within the last 30 days (primary outcome) among first year high school students (age 15-17 years) at intervention schools compared with control schools. Furthermore, the following research questions will be addressed:

- Can the 'High schools High on life' intervention lead to a lower mean weekly alcohol consumption, a lower alcohol intake at last school party, lower alcohol intake at the school during last school party and lower proportion of students who think alcohol plays a too dominant part at the school (secondary outcomes) among first year high school students at intervention schools compared with control schools?

- Does the 'High schools High on life' intervention lead to intended positive side effects among first year high school students at intervention schools?

- Does the 'High schools High on life' intervention lead to any unintended negative side effects among first year high school students at intervention schools?

- Is the effect of the 'High schools High on life' intervention on the primary outcome preceded by changes in the determinants (mediators) at intervention schools?

- Is there a different effect of the 'High schools High on life' intervention among girls versus boys, or students with high SEP versus low SEP at intervention schools?

- How does the implementation fidelity affect the effect of 'High schools High on life' intervention at intervention schools?

- Which factors are important in relation to the implementation of the intervention at intervention schools?

\section{Intervention}

The 'High schools High on life' intervention builds on a socioecological framework which recognises that adolescents' drinking behaviour is determined by a wide range of interacting factors on multiple levels. ${ }^{28}$ The multicomponent intervention targeting incoming first year high school students includes a school environmental component addressing school alcohol policies and norms, a school educational component addressing students' social norms around alcohol and a parental component addressing parents' knowledge and attitudes towards alcohol. The intervention will be delivered in the school year 2019-2020.

\section{The 'High schools High on life' components}

The intervention 'High schools High on life' was developed in collaboration between researchers, at the Centre for Intervention Research at the National Institute of Public Health, University of Southern Denmark and staff 
PROGRAM THEORY

INTERVENTION
COMPONENTS
- School environmental:
-Alcohol policy checklist
-Web-based education to
student social-and
introduction committees
- School educational:
-Pocket movie campaign
-Social norms campaign
-Morning party event
(voluntary)
- Parental:
-Parents meeting at the
high school
-Information website
-Information folder

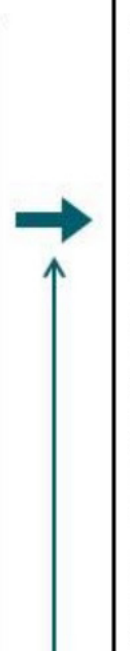

CHANGE IN DETERMINANTS

High school determinants:

-Clearer alcohol policies

The alcohol policy is communicated to students and parents

-Stronger enforcement of the alcohol policy

-More alcohol-free socialevents, than events where

alcohol issold

\section{$1^{\text {st }}$ year student determinants:}

$-1^{\text {st }}$ year students feel they are able to have fun without drinking

-Lower proportion of $1^{\text {st }}$ year students who overestimate the alcohol use among their peers

-Lower social pressure to drink

-Knowledge of the high schools' alcoholpolicy

Parental determinants:

Increased knowledge of parents influence on their child's drinking

-Talk to their child about alcohol

-Make rules on the child's alcohol use

-Knowledge of the high schools' alcoholpolicy

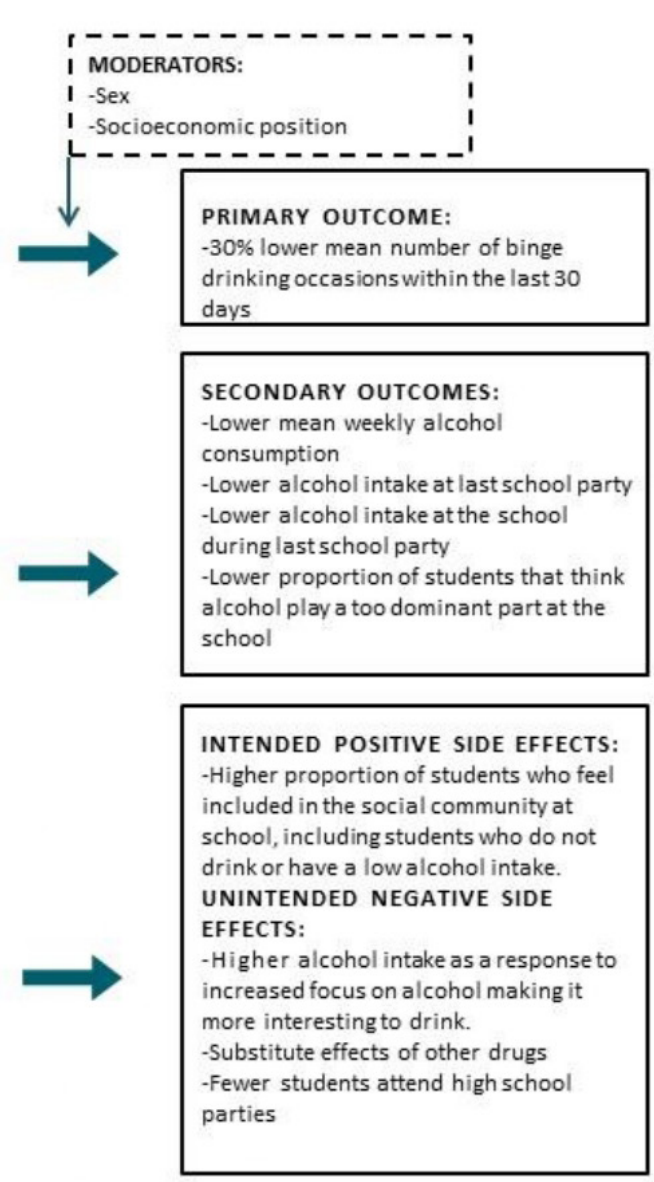

Figure 1 Programme theory of 'High schools High on life'.

from Section for Cancer Prevention and Information, the Danish Cancer Society in close consultation with school staff, pupils and parents. The development of the intervention was guided and inspired by the planning steps of the Intervention Mapping protocol, the behavioural change wheel, behavioural change techniques and theories, the best available evidence, new empirical studies of contextual factors influencing students' alcohol intake in the Danish high school setting and experiences, and ongoing local and national initiatives and campaigns targeting students' alcohol consumption at Danish high schools. ${ }^{29-32}$ In the following a short description of the main intervention components and mechanisms of change will be described and illustrated (figure 1). A comprehensive description of the intervention components and development of the intervention will be described elsewhere.

\section{School environmental component}

The school environmental intervention component is designed to restructure the physical and social school environment by limiting availability of alcohol at schools, creating a clear alcohol policy to be communicated to students, personnel and parents, and to facilitate implementation and enforcement of the school alcohol policy and create social activities not focusing on alcohol. The component consisted of an alcohol policy checklist to guide the school management's development of the school alcohol policy and web-based educations directed at the student social and introduction committees to motivate and guide student members to arrange social activities for their fellow students not focusing on alcohol.

\section{School educational component}

The school educational component is designed to change social norms around alcohol among first year students by correcting misperception on rates of peer alcohol use (behavioural norms) and the social acceptability of alcohol use (injunctive norms), making students reflect on their own alcohol use, and when they perceive it as fun and not fun to drink. ${ }^{33}$ Further, a pocket movie campaign in which the students promote the ideal of drinking less and experiencing more, inspired by induced compliance theory and a social norms campaign guided by the social norms approach, is included. ${ }^{3435}$ As a voluntary element schools could host (and receive support for) an alcoholfree morning party to give students an experience of partying without drinking.

\section{Parental component}

The parental component is designed to encourage parents of first year students to talk to their child about alcohol and come to a mutual agreement regarding the child's drinking habits. The parental component consists 


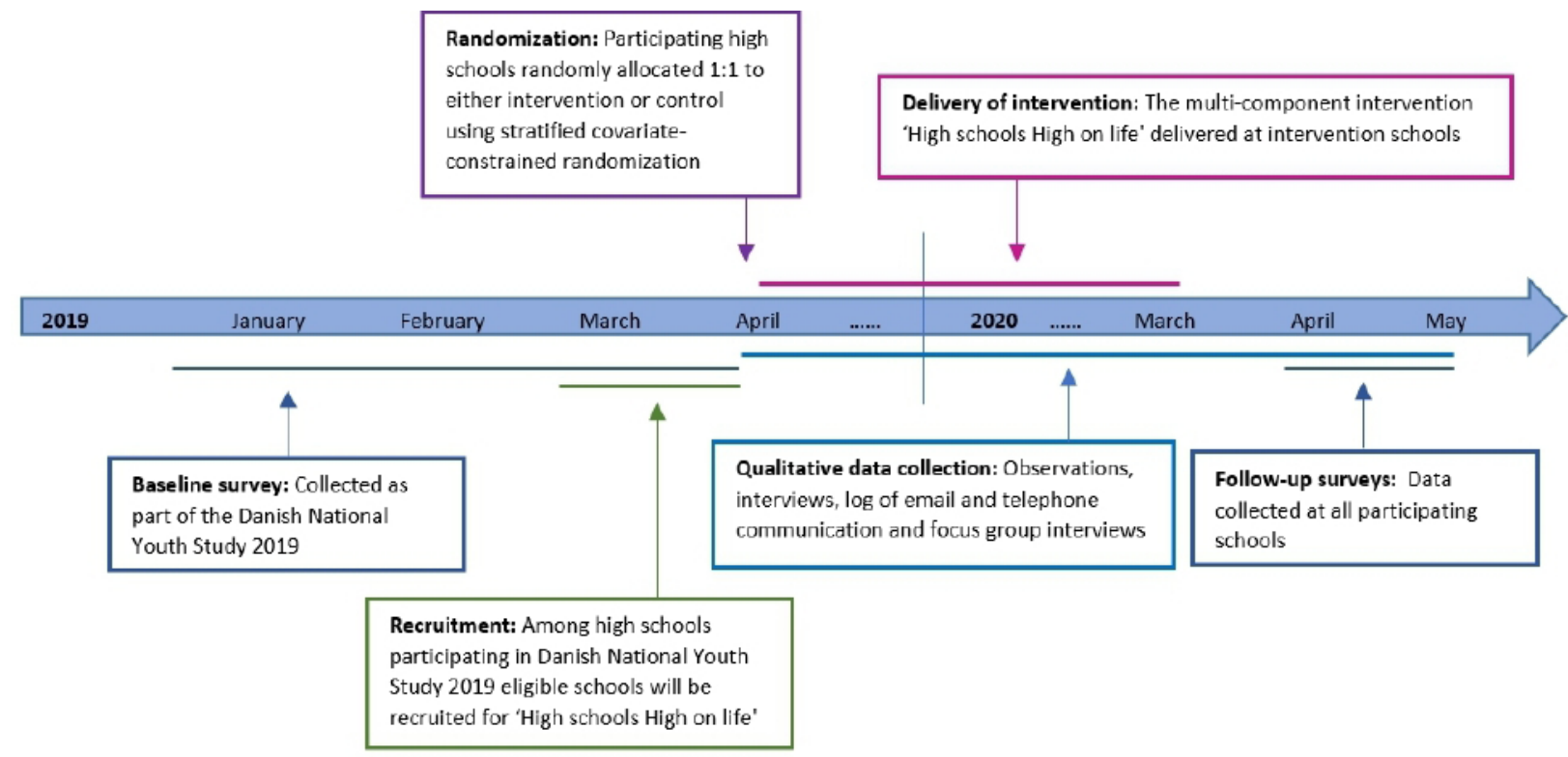

Figure 2 Timeline of the evaluation process.

of three separate elements: (1) an information meeting at the school in the beginning of the school year, where the parents are introduced to the school policy, encouraged to support it and discuss alcohol with their child, (2) an information folder about high school students' alcohol use and attitudes, and what parents can do to prevent heavy drinking among their children and (3) a website which aims to promote skill training among parents in discussing alcohol with the child.

\section{METHODS AND ANALYSIS}

\section{Study design}

Intervention effects will be evaluated in a two-armed cluster randomised controlled trial. Baseline information will be derived from first year students' responses to the Danish National Youth Study 2019, collected from 14 January to 30 March 2019 and follow-up information will be collected from a questionnaire to first year students in April to May 2020. The trial is registered prior to randomisation at ClinicalTrials.org (Trial registration number: NCT03906500). Intervention schools will be asked to introduce the 'High schools High on life' intervention components. Control schools will be asked to continue business as usual in the intervention period (April 2019 to March 2020) and will be offered the intervention afterwards (in the school year starting August 2020). A timeline of the evaluation process is provided in figure 2 . The study is considered to be an effectiveness trial as schools will be responsible for the implementation of the intervention. Researchers will, however, monitor and support the implementation at each school by frequent phone calls, observations at the school, newsletters and email reminders to local coordinators.

\section{Inclusion criteria}

- High schools which have previously participated in the Danish National Youth Study 2019.

- Institutions offering general high school examination.

- First year high school students.

\section{Recruitment}

High school will be recruited from participating high schools in The Danish National Youth Study 2019. First year students' responses to this survey will serve as the baseline for the evaluation of the 'High schools High on life' intervention. A total of 50 general high schools participated in The Danish National Youth Study 2019 (participation proportion: 33\%) and will be invited to participate in 'High schools High on life'. High schools will receive an email invitation to the research project and those who do not respond within two workdays will receive a phone call from the research group to describe the aim of the project in more details.

\section{Sampling}

Participating high schools will be randomly allocated 1:1 to either intervention or control using stratified covariateconstrained randomisation (CCR) ${ }^{36}$ The randomisation will be stratified on whether the school was an independent general high school or embedded within a broader youth educational institution, school size measured by total number of general high school students, proportion of parents with high educational level and degree of urbanisation. Information on parental educational level and degree of urbanisation was derived from theDanish National Youth Study 2014, and for institutions that did not participate in 2014 information was based on municipality information. The CCR statistical analysis system macro was used to balance these variables in the intervention and control schools. ${ }^{37}$ If schools accept to participate, 


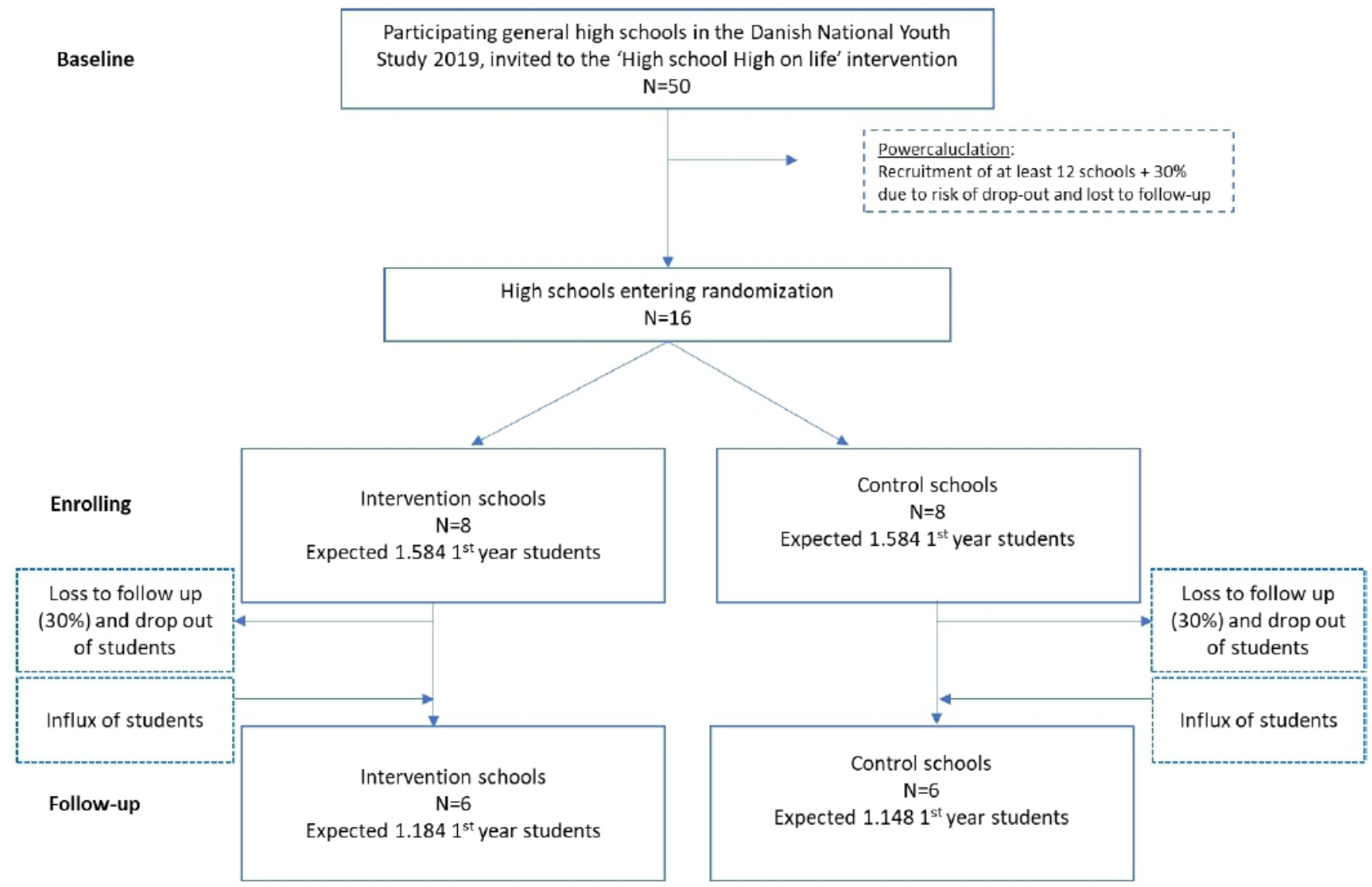

Figure 3 Flow chart of expected number of participating schools and students.

students are automatically enrolled and assigned to the intervention/control group the school is randomised to (figure 3).

\section{Data collection}

The student baseline questionnaire was based on items from other studies (eg, The Health Behavior in Schoolaged Children (HBSC) Study and the Danish National Youth Study 2014) either transferred without any revision or adapted to the high school setting. ${ }^{38} 39$ A few items were developed specifically to the 'High Schools High on life' intervention. The questionnaire was tested among four high school students (three girls and one boy) and followed by single interviews about comprehensiveness and layout. The questionnaire was modified according to the students' comments and suggestions. The Danish National Youth Study 2019 questionnaire took around $45 \mathrm{~min}$ to answer. All first year high school students in intervention and control schools will be asked to answer a study-specific follow-up questionnaire. The follow-up questionnaires will only include questions relevant to the intervention, and take around $15 \mathrm{~min}$ to answer, as school managers specifically demanded short surveys not to compromise on teaching hours. All student questionnaires will be web-based and answered in the classroom. Table 1 outlines questions answered in the student baseline questionnaire that will be repeated in the follow-up questionnaire (in a similar or modified version).
Researchers will monitor and support the implementation and try to prevent school drop-out by frequent phone calls, visits, newsletters and email reminders to local coordinators at schools.

\section{Outcomes}

The primary outcome is mean number of binge drinking episodes within the last 30 days. First year high school students will be asked 'how many times within the last 30 days have you been drinking 5 or more units of alcohol within one occasion? ${ }^{39}$. Mean number of binge drinking episodes within the last 30 days were chosen as the primary outcome of the intervention as (1) binge drinking is associated with increased risk injuries in adolescence and on the long term a wide range of diseases, ${ }^{40}$ (2) episodes of binge drinking is a global measure of risky alcohol use ${ }^{40}$ and (3) episodes of binge drinking is a broad measure of risky drinking patterns, that also take into account possible substitute effects e.g. if the alcohol intake moves to outside the school setting. Secondary outcomes are (1) mean weekly alcohol consumption, ${ }^{39}$ (2) mean alcohol intake at last school party, ${ }^{39}$ (3) mean alcohol intake at the school during last school party ${ }^{39}$ and (4) proportion of students who think alcohol plays a too dominant part at the school (table 1).

Explorative outcomes: intended positive side effects: higher proportion of students feels included in the social community at school, including stratified analysis among 
Table 1 Outcomes and mediators

\begin{tabular}{|c|c|c|c|}
\hline Variable & Question & Type & Units/categories \\
\hline \multicolumn{4}{|l|}{ Primary outcome } \\
\hline Binge drinking episodes & $\begin{array}{l}\text { Student questionnaire: How many times within the last } 30 \\
\text { days have you been drinking } 5 \text { or more units of alcohol } \\
\text { within one occasion? }\end{array}$ & Continuous & Episodes \\
\hline \multicolumn{4}{|l|}{ Secondary outcomes } \\
\hline Weekly alcohol consumption & $\begin{array}{l}\text { Student questionnaire: How many units of alcohol have you } \\
\text { been drinking on each day during the last week? }\end{array}$ & Continuous & Units of alcohol \\
\hline Alcohol intake at last school party & $\begin{array}{l}\text { Student questionnaire: How many units of alcohol did you } \\
\text { drink at the last high school party you attended? }\end{array}$ & Continuous & Units of alcohol \\
\hline $\begin{array}{l}\text { Alcohol intake at the school during } \\
\text { last school party }\end{array}$ & $\begin{array}{l}\text { Student questionnaire: How many units of alcohol did you } \\
\text { drink at the school during the last high school party you } \\
\text { attended? }\end{array}$ & Continuous & Units of alcohol \\
\hline $\begin{array}{l}\text { Proportion of first year high school } \\
\text { students who think alcohol plays a } \\
\text { too dominant role at the school }\end{array}$ & $\begin{array}{l}\text { Student questionnaire: Do you feel that alcohol plays a } \\
\text { too dominant role at your high school (eg, at high school } \\
\text { parties, school bars, introduction trips, study tours, the } \\
\text { general conversation etc.)? }\end{array}$ & Binary & Yes/no \\
\hline
\end{tabular}

Explorative outcomes

Intended positive side effects

Proportion of first year high school Student questionnaire: Are you part of the social students who feel included in the social community at school

\section{Proportion of first year high school students who feel included in the social community at school in the total student population and among students who do not drink or have a low alcohol intake (25\% lowest quantile in mean weekly alcohol consumption among first year students at baseline).}

Unintended negative side effect

Weekly alcohol consumption

Consumption of drugs.

School party attendance

School party attendance

Mediators (determinants)

A clear alcohol policy

Student questionnaire: Are you part of the social community at your school?

Binary community at your school?

'yes, sometimes' vs

'occasionally', 'seldom' or 'never'

Binary 'Yes, always' or' yes, sometimes' vs 'occasionally', 'seldom' or 'never'

Student questionnaire: How many units of alcohol have you Continuous Units of alcohol been drinking on each of the days during the last week?

Student questionnaire: Have you ever tried to smoke Binary Yes/no marihuana, weed or pot?

Student questionnaire: Have you ever tried other drugs Binary Yes/no than marihuana?

Student questionnaire: Have you ever attended a school Binary Yes/no party?

Manager/coordinator questionnaire: In this school year (2019/2020): Did you introduce a new or change your alcohol policy?

Binary

\footnotetext{
Alcohol policy communicated to students and parents
}

Manager/coordinator questionnaire: In this school year (2019/2020): Was the alcohol policy communicated to parents of 1 st year students?

Manager/coordinator questionnaire:

In this school year (2019/2020): Was the alcohol policy communicated to students? 


\section{Table 1 Continued}

\begin{tabular}{|c|c|c|c|}
\hline Variable & Question & Type & Units/categories \\
\hline Enforcement of the alcohol policy & $\begin{array}{l}\text { Student questionnaire: } \\
\text { Is it your experience that... } \\
\text { Alcohol is sold at most social events at your high } \\
\text { school? } \\
\text { Students are denied entrance to school parties or sent } \\
\text { home if they are visibly drunk? } \\
\text { Nobody drinks alcohol on introduction trips? } \\
\text { Nobody drinks alcohol on study trips? } \\
\text { Invitations to school parties do not encourage heavy } \\
\text { drinking? }\end{array}$ & Binary & $\begin{array}{l}\text { 'Highly agree' or 'agree' vs } \\
\text { 'neither agree nor disagree', } \\
\text { 'disagree' or 'highly } \\
\text { disagree' }\end{array}$ \\
\hline
\end{tabular}

\section{More alcohol-free social events, than events where alcohol is sold \\ Alcohol policy checklist reported by school principals Student questionnaire: \\ Alcohol is sold at most social events outside school hours at my high school} students who overestimate the alcohol use among their peers

Student questionnaire: At your high school: How many units of alcohol do you think other young people of the same gender and school year as you drank at the last high
Proportion of first year high school

\section{Binary}

\section{Yes/no}

'Highly agree' or 'agree' vs 'neither agree nor disagree', 'disagree' or 'highly disagree' school party you attended?

Proportion of first year high school students who have felt a social pressure to drink

Proportion of first year high school students who feel they can have fun without drinking

Proportion of first year high school students who are familiar with the high schools' alcohol policy

Student questionnaire: Do you know if your high school has Binary an alcohol policy?

Suestionnaire: How often have you experienced any of the situations described below? I have felt a pressure to drink more that I would like to.

Student questionnaire: To which degree do you agree in the Binary following...- I can have fun at a party without drinking

\section{Binary}

Proportion who overestimates their peers' mean alcohol intake at the school during last school party

\section{Binary 'Often' or 'sometimes' vs} 'seldom' or 'never'

'Highly agree' or 'agree' vs 'neither agree nor disagree', 'disagree' or 'highly disagree'

\section{'Yes, we do, and I know the} content' vs' yes, we do but I do not know the content', 'no, we don't', or 'I do not know if my high school has an alcohol policy'

Proportion of first year high school Student questionnaire: Have you talked to your parents students who talk to their parents about your use of alcohol?

Binary

'Yes, we talk about it regularly' vs 'yes, we have talked about it once, recently', 'yes, we talked about it a long time ago' or 'no, we have never talked about it'.

Proportion of first year high school students who have agreements with their parents on how much Student questionnaire: Do you have agreements with your Binary parents about your alcohol consumption? students who do not drink or have a low alcohol intake (25\% lowest quantile in mean weekly alcohol consumption at baseline among students in both interventions and control group). Unintended negative side effects: higher weekly alcohol intake among students in the intervention group as a response to increased focus on alcohol or a substitution effect where a higher proportion of student in the intervention group have tried marihuana, weed, pot or other drugs.

\section{Change in determinants (mediators)}

As outlined in the programme theory (figure 1), we expect to see a difference between intervention and control high schools at follow-up in a range of determinants of excessive drinking addressed by the multiple intervention components. At the high school level, we expect clearer alcohol policies, reduced availability of alcohol, communication of the policy to students and parents, stronger enforcement of the alcohol policy, and more alcoholfree social events at intervention schools compared with control schools. At the student level, we expect larger proportions of students at intervention schools compared with control schools who feel they can have fun without drinking, who are familiar with the high schools' alcohol policy, who talk to their parents about alcohol, and who have rules/agreements with their parents on how much they can drink. Additionally, we expect smaller proportions of students who overestimates the alcohol use among their peers and who has felt a social pressure to 
drink at intervention schools compared with control schools. These variables and their operationalisation are presented in table 1 .

\section{Planned statistical analysis}

A blinded version of the data will be used for data analysis. In the primary analysis, outcomes will be analysed after the intention-to-treat principle including all students in the arm to which they were allocated independently of whether they received (or completed) the intervention as planned. Intention-to-treat analysis will be supplemented by perprotocol analysis taking the implementation dose of intervention components into account (both at the school and the individual level). Dose delivered will be measured in the coordinator questionnaire and by observations and will be defined as the number of intervention components delivered as planned) and dose received will be measured in the student questionnaire and will be defined as the number of intervention components received as planned. Multilevel models will be used to account for the clustering of students in schools and school classes. General and generalised linear models will be used to study continuous and binary outcomes. If the model assumptions of the general linear model are not fulfilled, transformation of the outcome will be performed. Non-responses will be handled by weighting based on socio-demographic variables such as sex, parents' socioeconomic position and school region. As the baseline population is different from the follow-up population, all analyses will be adjusted for school level information on baseline outcome level, sex, parental education level and parental income, whether the school was an independent general high school or embedded within a broader youth educational institution, school size measured by total number of general high school students and degree of urbanisation to increase precision. If the number of missing outcomes is larger than $10 \%$ and the results of the primary outcome is significant, a worst-case scenario will be performed for the primary and secondary outcomes as sensitivity analyses. The missing outcome values in the one group will be imputed with the mean value of the primary or secondary outcome of the other group and vice versa.

The primary outcome will be tested with significance level of $5 \%$. Analyses of the predefined secondary outcomes will be analysed with no p-value adjustment due to multiplicity and the interpretation of these results will be assessed in the light of multiple testing. No significance testing will be performed for the exploratory outcomes.

Differential effects of intervention on the primary outcome by sex and parental educational level will be investigated by stratification (explorative analyses). We hypothesise that boys may experience stronger intervention effects than girls due to higher initial level of binge drinking. ${ }^{41}$ We have no hypotheses of the direction of socioeconomic differences in intervention effects, as previous research has been inconsistent in the direction of intervention effects in different socioeconomic groups. ${ }^{42} 43$

We will apply mediation analysis to test our programme theory and hypothesised assumptions of whether changes in specific determinants will lead to changes in the primary outcome. $^{44}$

\section{Sample size calculation}

Prior to the study, a sample size calculation was performed using the statistical software STATA V.15 applying Sampsi and Sampclus to assess number of high schools and students needed to recruit to evaluate the effects of the intervention. Based on results from the unplugged programme, ${ }^{45}$ a previous school-based substance abuse prevention programme among junior high school students (12-14years old) which has been tested in a large crossnational study in seven European countries, we expected a $30 \%$ lower mean number of binge drinking episodes within the last 30 days in the intervention group as compared with the control group at follow-up. The average number of binge-drinking episodes within the last 30 days was estimated based on data from the Danish National Youth Study $2014^{39}$ with an average of 198 enrolled firstyear students per high school (cluster size). In 2014, high school students had an average of 2.94 binge drinking episodes within the last 30 days, with an SD of 2.58, and an intraclass correlation of 0.034 . Conventional levels of statistical power (0.8) and level of significance (0.05) were used. Under the assumptions above, calculations showed that at least 12 high schools should be recruited for the study to show a $30 \%$ reduction in the number of binge-drinking episodes within the last 30 days (six control schools and six intervention schools, equivalent to a total of 2296 students). Due to the risk of lost to follow-up, we aimed at recruiting an additional $30 \%$ of schools, corresponding to 16 high schools and 3168 students. Flowchart of expected number of participating schools and students is presented in figure 2 .

\section{Process evaluation}

We will perform a process evaluation study in order to explore and assess the implementation process and explain the effect or lack of effect of the intervention. The process evaluation will be inspired by a six step protocol for systematic process evaluation developed by Aarestrup et $a l .{ }^{46}$ Grant $e t$ al.'s framework for process evaluation of cluster randomised trials of complex interventions ${ }^{47}$ and the factors identified by Durlak and DuPre that effects implementation. ${ }^{48}$ We will combine qualitative and quantitative methods to gain information on (1) the dose, quality and participant responsiveness of the intervention delivered to school coordinators, parents and the student social and introduction committees, (2) the dose, quality and student responsiveness of the intervention delivered from school coordinators, parents and social and introduction committees to first year students, (3) factors affecting implementation (community factors, provider characteristics, innovation characteristics, organisational capacity and training and technical assistance) and (4) contamination at intervention and control schools. 


\section{Qualitative methods}

Qualitative data will be collected at intervention schools continuously throughout the implementation period including (1) participant observations of the parent information meeting and students' engagement with the webbased education programmes (2) interviews with school coordinators (in person and via telephone), (3) focus group interviews with first year students and members of the student social and introduction committees and (4) $\log$ of email and telephone communication between the research team and school coordinators.

\section{Quantitative methods}

Quantitative data will be collected at follow-up (April to May 2020) at intervention and control schools using student questionnaires and school coordinator telephone interviews. This data will provide information on the intervention dose delivered to school coordinators, the social and introduction committees, parents and first year students, school context and contamination at both intervention and control schools. Website track records will contribute with information on parental use of the 'High schools High on life' website.

\section{Patient and public involvement}

No patient involved.

\section{ETHICS AND DISSEMINATION OF RESULTS \\ Ethics}

In Denmark, behavioural health promotion interventions are generally not required to notify for ethic approval by the Scientific Ethics Committees. ${ }^{49}$ The Scientific Ethics Committee for the Capital Region of Denmark has declared that the trial is not subject to notification (jnr. 19021957). The study is registered at the Research an Innovation Office at University of Southern Denmark (ref: 10.314) allowing collection of personal data. When inviting the high schools to participate, school managers received written information about the study. Students were informed that participation was voluntary that their information would be used for research purposes only and treated confidentially. Research has been inconclusive regarding the existence of a substitution effect between alcohol and cannabis. ${ }^{50}$ Possible, unintended negative side effects of the intervention, such as shifting to other drugs as replacement for diminished alcohol use, increased alcohol use due to increased attention to the subject, or other side effects will be monitored in the process evaluation. No other ethical concerns were identified.

\section{Dissemination of results}

The trial results will be communicated to other researchers in peer-reviewed journals and scientific conferences. Furthermore, they will be disseminated to the public, schools and public health practitioners through press releases, school health profiles to all participating schools based on questionnaire data and conferences for schools and municipalities working with alcohol prevention.

\section{DISCUSSION}

The 'High schools High on life' intervention aims at providing important insights into effective strategies to reduce excessive alcohol consumption among adolescents. Further the study, aims at providing knowledge on implementation processes, and intervention effects among different subgroups, and contribute to the literature on cultural changes in educational institutions.

Trials are expensive and recruitment of schools to research projects can be challenging, it is, therefore, important to use research data efficiently. ${ }^{51}$ The recruitment to the intervention was based on existing baseline data which represents an efficient use of data and gives a unique opportunity to study selection bias in participation. However, schools that did not participate in the Danish National Youth Study 2019 (67\%) were not invited to participate in the evaluation of the 'High schools High on life' intervention. This reduced the number of high schools that was invited to participate and may reproduce selection bias from the Danish National Youth Study 2019.

Schools will mainly deliver the intervention components themselves. The implementation of the intervention components will be followed closely to support and learn from the implementation processes. The project groups' efforts to secure full implementation will be described thoroughly in the process evaluation as it is important to know the schools' specific need for implementation support for future scale up of the intervention.

Acknowledgements The 'High schools High on life' project group would like to thank all high schools, students, teachers, and school managers who helped designing the intervention.

Contributors MG and JST concepted the original idea of the study. VSCP wrote the first draft of the manuscript in collaboration with SH. JAR wrote the first draft of the process evaluation section. LT, RK and JST advised the evaluation design and statistical analysis. All authors read, revised and approved the final manuscript.

Funding This research was funded by the Danish Cancer Society. Trial Sponsor Contact: Anne Mette Bak. The Danish Cancer Society, grants, Strandboulevarden 49, 2100 Copenhagen, Denmark phone:+45 35257257

Competing interests The Danish Cancer Society developed intervention materials based on an ongoing campaign. The Danish Cancer Society had no influence on the study design, data analysis or interpretation of data.

Patient and public involvement Patients and/or the public were involved in the design, or conduct, or reporting, or dissemination plans of this research. Refer to the Methods section for further details.

Patient consent for publication Not required.

Provenance and peer review Not commissioned; externally peer reviewed.

Open access This is an open access article distributed in accordance with the Creative Commons Attribution Non Commercial (CC BY-NC 4.0) license, which permits others to distribute, remix, adapt, build upon this work non-commercially, and license their derivative works on different terms, provided the original work is properly cited, appropriate credit is given, any changes made indicated, and the use is non-commercial. See: http://creativecommons.org/licenses/by-nc/4.0/.

ORCID iD

Veronica Sofie Clara Pisinger http://orcid.org/0000-0002-5605-138X 


\section{REFERENCES}

1 Rehm J, Baliunas D, Borges GLG, et al. The relation between different dimensions of alcohol consumption and burden of disease: an overview. Addiction 2010;105:817-43.

2 Mokdad AH, Forouzanfar MH, Daoud F, et al. Global burden of diseases, injuries, and risk factors for young people's health during 1990-2013: a systematic analysis for the global burden of disease study 2013. Lancet

3 Kraus L, Guttormsson U, Leifman $\mathrm{H}$, et al. Results from the European school survey project on alcohol and other drugs 2016. publications office of the European Union, 2015.

4 Rasmussn M, Pedersen TP, Due P. Skolebørnsundersøgelsen 2015. Statens Institut for Folkesundhed, 2014.

5 Inchley J, Currie D. Growing up unequal: gender and socioeconomic differences in young people's health and well-being. Health Behaviour in School-aged Children (HBSC) study: international report from the. 2013, 2014.

6 Brink AS A. Unges livsstil OG dagligdag 2008, MULD rapport NR. 7. Sundhedstyrrelsen \& Kræftens Bekæmpelse, 2008.

7 Nielsen JC, Sørensen NU, Ozmec MN. Når det ER svært at være Ung I DK: unges trivsel OG mistrivsel I TAL, 2010.

8 Bendtsen P, Mikkelsen SS, Tolstrup JS. Ungdomsprofilen 2014. Statens Institut for Folkesundhed, SDU, 2015.

9 Rehm J, Mathers C, Popova S, et al. Global burden of disease and injury and economic cost attributable to alcohol use and alcohol-use disorders. The Lancet 2009;373:2223-33.

10 Andersen A, Due P, Holstein BE, et al. Tracking drinking behaviour from age 15-19 years. Addiction 2003;98:1505-11.

11 Eliasen M, Kaer SK, Munk C, et al. The relationship between age at drinking onset and subsequent binge drinking among women. Eur $J$ Public Health 2009;19:378-82.

12 Jefferis $\mathrm{BJMH}$, Power $\mathrm{C}$, Manor O. Adolescent drinking level and adult binge drinking in a national birth cohort. Addiction 2005;100:543-9.

13 Pitkänen T, Lyyra A-L, Pulkkinen L. Age of onset of drinking and the use of alcohol in adulthood: a follow-up study from age 8-42 for females and males. Addiction 2005;100:652-61.

14 Hingson RW, Heeren T, Winter MR. Age at drinking onset and alcohol dependence: age at onset, duration, and severity. Arch Pediatr Adolesc Med 2006;160:739-46.

15 Griffin KW, Botvin GJ. Evidence-Based interventions for preventing substance use disorders in adolescents. Child Adolesc Psychiatr Clin N Am 2010;19:505-26.

16 Foxcroft DR, Tsertsvadze A. Cochrane review: universal schoolbased prevention programs for alcohol misuse in young people. Evidence-Based Child Health: A Cochrane Review Journal 2012;7:450-575.

17 Foxcroft DR, Tsertsvadze A. Universal multi-component prevention programs for alcohol misuse in young people. The Cochrane Library, 2011.

18 Das JK, Salam RA, Arshad A, et al. Interventions for adolescent substance abuse: an overview of systematic reviews. J Adolesc Health 2016:59:S61-75.

19 Cuijpers P. Effective ingredients of school-based drug prevention programs. A systematic review. Addict Behav 2002;27:1009-23.

20 Carey KB, Scott-Sheldon LAJ, Elliott JC, et al. Face-To-Face versus computer-delivered alcohol interventions for College drinkers: a meta-analytic review, 1998 to 2010. Clin Psychol Rev 2012;32:690-703.

21 Barnett NP, Read JP, JPJJoSAT R. Mandatory alcohol intervention for alcohol-abusing college students: a systematic review. J Subst Abuse Treat 2005;29:147-58.

22 Fachini A, Aliane PP, Martinez EZ, et al. Efficacy of brief alcohol screening intervention for college students (basics): a meta-analysis of randomized controlled trials. Subst Abuse Treat Prev Policy 2012;7:1.

23 Seigers DKL, Carey KB. Screening and brief interventions for alcohol use in college health centers: a review. J Am Coll Health 2010;59:151-8.

24 Bhochhibhoya A, Hayes L, Branscum P, et al. The use of the Internet for prevention of binge drinking among the College population: a systematic review of evidence. Alcohol Alcohol 2015;50:526-35.

25 Braitman AL, Lau-Barraco C. Personalized boosters after a computerized intervention targeting College drinking: a randomized controlled trial. Alcohol Clin Exp Res 2018;42:1735-47.

26 Eliasen M, Rod MH, Flensborg-Madsen T, et al. The association between blood alcohol content and cheerfulness, focus distraction, and sluggishness among young adults attending high school parties. Alcohol Clin Exp Res 2014;38:826-33.

27 Beck S, Reesen S. Festkultur OG rusmidler I gymnasieskolen. Dansk Institut for Gymnasiepaedagogik, Syddansk Universitet, 2004

28 Dahlgren G, Whitehead M. Policies and strategies to promote social equity in health. Stockholm: Institute for future studies, 1991.

29 Eldredge LKB, Markham CM, Ruiter RA, et al. Planning health promotion programs: an intervention mapping approach. John Wiley \& Sons, 2016.

30 Michie S, Richardson M, Johnston M, et al. The behavior change technique taxonomy (V1) of 93 hierarchically clustered techniques: building an international consensus for the reporting of behavior change interventions. Ann Behav Med 2013;46:81-95.

31 Craig P, Dieppe P, Macintyre S, et al. Developing and evaluating complex interventions: the new medical Research Council guidance. BMJ 2008;337:a1655.

32 Michie S, van Stralen MM, West R, RJIs W. The behaviour change wheel: a new method for characterising and designing behaviour change interventions. Implementation Sci 2011;6.

33 Moreira MT, Smith LA, Foxcroft D. Social norms interventions to reduce alcohol misuse in University or college students. Cochrane Database Syst Rev.2009;3.

34 Perkins $\mathrm{H}$. The social norms approach to preventing school and College age substance abuse: a Handbook for educators, counselors, and clinicians. Jossey-Bass, 2003.

35 Natvig H, Aarø LE. Effects of induced compliance on alcohol use: evaluation of a school-based intervention among Norwegian 8th graders. Nord Psychol 2014;66:2-19.

36 Ivers NM, Halperin IJ, Barnsley J, et al. Allocation techniques for balance at baseline in cluster randomized trials: a methodologica review. Trials 2012;13.

37 Greene EJ. A SAS macro for Covariate-Constrained randomization of general cluster-randomized and Unstratified designs. J Stat Softw 2017:77: jss.v077.c01.

38 Currie C, Zanotti C, Morgan A. Social determinants of health and well-being among young people. health behaviour in school-aged children (HBSC) study: international report from the 2009/2010 survey. Copenhagen: WHO Regional Office for Europe, 2012.

39 Pisinger V, Mikkelsen SS, Bendtsen P, et al. The Danish national youth study 2014: study design, population characteristics and non-response analysis. Scand J Public Health 2020;48:1403494817729283.

40 Kuntsche E, Kuntsche S, Thrul J, et al. Binge drinking: health impact, prevalence, correlates and interventions. Psychol Health 2017;32:976-1017.

41 Bramming M, Møller SP, Pisinger V. Alkohol blandt gymnasie-og erhvervsskoleelever: Alkoholvaner alkoholkultur OG trivsel, 2018.

42 Moore GF, Littlecott HJ, Turley R, et al. Socioeconomic gradients in the effects of universal school-based health behaviour interventions: a systematic review of intervention studies. BMC Public Health 2015;15:907.

43 Caria MP, Faggiano F, Bellocco R, et al. The influence of socioeconomic environment on the effectiveness of alcohol prevention among European students: a cluster randomized controlled trial. BMC Public Health 2011;11:312.

44 Lange T, Hansen KW, Sørensen R, et al. Applied mediation analyses: a review and tutorial. Epidemiol Health

45 Faggiano F, Galanti MR, Bohrn K, et al. The effectiveness of a school-based substance abuse prevention program: EU-Dap cluster randomised controlled trial. Prev Med 2008;47:537-43.

46 Aarestrup AK, Jørgensen TS, Due P, et al. A six-step protocol to systematic process evaluation of multicomponent clusterrandomised health promoting interventions illustrated by the boost study. Eval Program Plann 2014;46:58-71.

47 Grant A, Treweek S, Dreischulte T, et al. Process evaluations for cluster-randomised trials of complex interventions: a proposed framework for design and reporting. Trials 2013;14:15.

48 Durlak JA, DuPre EP. Implementation matters: a review of research on the influence of implementation on program outcomes and the factors affecting implementation. Am J Community Psychol 2008;41:327-50

49 NVK. Scientific ethics Commitees, 2019. Available: http://www.nvk $\mathrm{dk} /$ forsker/naar-du-anmelder/hvilke-projekter-skal-jeg-anmelde

50 Subbaraman MS. Substitution and complementarity of alcohol and cannabis: a review of the literature. Subst Use Misuse

51 Kane R, Wellings K, Free C, et al. Uses of routine data sets in the evaluation of health promotion interventions: opportunities and limitations. Health Educ 2000;100:33-41. 